Mifsud, Aurora Rubio.

Conservadora-Restauradora, Doctora en Bellas Artes. Grupo de investigación Magistri Mediterranei, Departament d'Art i Musicología, UAB.

Má Antonia Zalbidea Muñoz.

Profesor Titular del Departamento de Conservación y Restauración de Bienes Culturales. Grupo de investigación Magistri Mediterranei, Departament d'Art i Musicología, UAB.

\title{
Estudio comparativo de la pintura mural gótica valenciana a partir de elementos de estilo y materiales representativos.
}

\section{Comparative study of Valencian gothic mural painting using style elements and representative materials.}

TIPO DE TRABAJO:

Comunicación.

PALABRAS CLAVE:

Pintura gótica valenciana, materiales pictóricos.

KEY WORDS:

Valencian Gothic painting, pictorial materials.

\section{RESUMEN}

Se presenta en esta comunicación parte del trabajo de investigación realizado en la tesis doctoral "La pintura mural gòtica lineal a territori valencià. Statu quo del corpus conegut. Estudi i anàlisi per a la seua conservació" (2015), en la que se ha catalogado el corpus de pinturas murales góticas lineales conservadas en territorio valenciano.

En éste trabajo se han identificado 34 edificaciones, que contienen total o parcialmente restos de 71 conjuntos decorativos (figurativos, decorativos y arquitectónicos) con características góticas, y sigue abierto debido a nuevas investigaciones en curso y continuos descubrimientos de pinturas que se continúan produciendo.

En la investigación, se han analizado individualmente los conjuntos pictóricos murales góticos, identificando circunstancias históricas y geográficas, antecedentes y referencias en otras artes, además del estudio del estado de conservación, el modo de factura y la analítica de componentes, con el fin de encontrar trazos comunes que definen el corpus existente.

Se ha encontrado una amplia variedad de temas representados, de recursos decorativos y estilísticos, determinando que existen temáticas diversas, elementos ornamentales, estructuras de distribución, y modelos que conforman un rico panorama artístico. Se presenta en este trabajo el análisis comparativo a nivel estilístico y matérico a partir de los rasgos comunes detectados a en los distintos conjuntos pictóricos.

En el ámbito estilístico (presentado en este artículo), se estudian la totalidad de los conjuntos identificados, independientemente de que se ubiquen en el periodo gótico inicial o más evolucionado, o de que conformen decoraciones de tipo arquitectónico. 


\section{ABSTRACT.}

We present in this communication part of the research work carried out in the doctoral thesis "La mural mural gòtica lineal a territori valencià. Status quo of the corpus conegut. Study for its conservation"(2015), which has cataloged the corpus of linear Gothic paintings conserved in Valencian territory.

In this work, 34 buildings have been identified, which contain totally or partially remains of 71 decorative sets (figurative, decorative and architectural) with Gothic characteristics, and is still open due to new researches in progress and continuous discoveries of paintings that continue to be produced.

In the investigation, the Gothic mural paintings were analyzed individually, identifying historical and geographical circumstances, background and references in other arts, as well as the study of conservation status, invoice mode and component analysis, in order to find Common features that define the existing corpus.

It has been found a wide variety of themes represented, of decorative and stylistic resources, determining that there are diverse themes, ornamental elements, distribution structures, and models that make up a rich artistic panorama. We present in this work the comparative analysis at the stylistic and material level based on the common traits detected a in the different pictorial sets.

In the stylistic area (presented in this article), all of the identified sets are studied, regardless of whether they are located in the initial Gothic period or more evolved, or that conform architectural decorations.

\section{CONTENIDO.}

\section{INTRODUCCIÓN.}

Este trabajo presenta el estudio del corpus de pinturas murales del periodo gótico inicial, existentes en el actual territorio de la Comunidad Valenciana, desde una óptica técnica, tanto a nivel estilístico como matérico. En este artículo se presentan los resultados obtenidos del estudio partir de elementos de estilo y materiales representativos.

En el estudio, se han identificado un total de 34 edificaciones, que contienen total o parcialmente restos de 71 conjuntos decorativos (figurativos, decorativos y arquitectónicos) con características góticas. De este total, 24 construcciones contienen 40 conjuntos donde aparece figuración gótica, 24 con trazos lineales y 16 de factura tardía. A menudo, el lamentable estado de conservación o los pocos restos que nos han reunido, han imposibilitado la identificación de aquello que representaban.

Se relacionan a continuación los elementos identificados, según tipologías y modelos, a los varios conjuntos pictóricos. Se así que se localizan estos cuantificando y calificando su número, y determinando su profusión. Se separan según contengan pinturas figurativas o elementos decorativos.

En las pinturas figurativas se corrobora la tipología de la representación, si es en forma de retablo y si se presenta enmarcado. Se identifican las dimensiones de las figuras humanas, y su variación dentro de tres tipos de tamaño: grandes, más de $50 \mathrm{~cm}$, medias entre 50 y $35 \mathrm{~cm}$ y pequeñas, de menos de $35 \mathrm{~cm}$. Además se identifica cuáles presentan representaciones de animales, de vegetación, y con textos al interno de las representaciones. Se localizan además la existencia añadida de dibujos hechos con carboncillo o con otros materiales.

Los conjuntos góticos lineales en territorio valenciano presentan una amplia variedad de temas, de recursos decorativos y estilísticos. Existen temáticas diversas, profana y religiosa; elementos decorativos, estructuras de distribución, y modelos que conforman un rico panorama artístico. Estos modelos que se encuentran seriados en un mismo conjunto pictórico e incluso repetidos a lo largo de la geografía, se podrían denominar característicos, aunque no son originales e inéditos del territorio estudiado. Se encuentran semejantes en otros lugares, y además en otras artes distintas a la pintura mural.

Con este hecho se pone de manifiesto que, con total probabilidad, existiría un movimiento de artistas dentro de la misma Corona de Aragón, o provenientes del resto de la península y otros países europeos, además del resto de la mediterránea, y con ellos se produciría un intercambio intelectual, y puede ser que incluso físico, de modelos. Los ejemplos que han llegado hasta hoy, son una pequeña muestra de las pinturas murales fruto de los artistas y artesanos autóctonos, y otros que conforman esta ósmosis europea. 
También se realiza una elenco de la temática general de las escenas figurativas, los tipos de personajes que representan, y aspectos particulares sobre algunos de ellos.

Hacia los elementos decorativos, se relaciona: si son de construcción arquitectónica y de qué se trata; la temática representada y si presentan un fondo característico. De elementos de construcción arquitectónica se relacionan los fingidos de artesonados y de sillares, además de las líneas constructivas de nivel. Para la temática que representan los elementos que contienen se han visto: elementos heráldicos, cortinajes y representaciones edilicias. Y para los tipos de fondos especiales, los vallados y fondos estrellados.

Una vez presentada toda esta información, se sintetiza en dos cuadros resumen, el primero sobre representaciones figurativas y el otro sobre elementos decorativos. En los cuadros se visualiza con claridad todos los datos expuestos, y se pueden hacer estudios comparativos sobre el número de elementos coincidentes, estableciendo así conexiones entre todos los conjuntos identificados. Se expone a continuación a relatar la información extraída durante la catalogación previa de los conjuntos pictóricos góticos valencianos.

Se han encontrado representaciones figurativas, de personas y también representaciones animales como parte de escenas. Escenas que forman parte de retablos; enmarcados por cenefas, o como imágenes individuales enmarcadas por cintas o arquitecturas. Además se encuentran que forman parte de conjuntos pictóricos más complejos, dentro de bandas horizontales que recorren la totalidad de los menajes de una sala a modo de friso; o incluso restos que se encuentran inconexos por la descontextualización de los fragmentos conservados.

Se han identificado representaciones figurativas en forma de retablo (que en la mayor parte de los casos no conservan la totalidad de las escenas), que narran las vidas de Santos, de Cristo o de la Virgen María. Además se han encontrado cenefas de tipo dentado o cintas enlazadas, como marcos en estas representaciones tipos retablo. Se han reconocido: en Castellfabib el retablo de la Pasión enmarcado por cenefas de frisos dentados en tricromía; en Vilafamés el retablo de la Virgen María de escenas también enmarcadas por cenefas de frisos dentados, y además inscritas en arquitecturas fingidas góticas; en Alcublas el retablo de la vida de San Antonio; en Llíria en la iglesia de la Sangre, el retablo San Pere de Verona y el retablo de la vida de Santa Bárbara, -enmarcados por dos líneas igual que los fingidos de sillares-; en Valencia en la Catedral, en el reconditorio las escenas de la pasión; también en Valencia en la iglesia de San Juan del Hospital, en la Capilla de Santo Miquel el retablo del mismo nombre y la escena alegórica de la Iglesia, donde la cenefa tipo dentado remata toda la capilla perfilando el arco toral; en Carcaixent a la ermita de Ternils, todavía ocultas, que pero por la bibliografía se sabe que correspondería con una Santa Cena; en Xàtiva en la iglesia de Sant Feliu tres retablos distintos, el de Santo Nicolau, el del Salvador y el de la Virgen María. También en Xàtiva al claustro del Convento de San Domènech, cintas enlazadas enmarcando el que podría ser el retablo de Santo Miquel; al Palacio Viejo de Llutxent a las pinturas de la sala noble, como remado superior al friso decorativo se han encontrado frisos dentados, y en Gandía en el Palacio Ducal, en la sala de la Cinta.

Marcos representados con cenefas vegetales enmarcadas dentro de una banda de color plano se han detectado en: la Pobla de Vallbona en los dos retablos el de la Vida de la Virgen María, y el retablo de los Santos Gil, Abdón y Senén enmarcados por arcos poli lobulados; en Llíria en la zona antigua del lado del evangelio; en Sagunto, en la pintura del hostal de la Castellona, y en Llutxent en las goteras del cortinaje y en la cenefa inmediata superior (ver llustración 1).

Marcos de retablo con forma de arcos poli lobulados con la función de enmarcar escenas pictóricas se encuentran en: Vilafamés en la iglesia de la Sangre; en Además a la ermita de la Virgen de la Huerta; en Alcublas al retablo de San Antonio; en la Pobla de Vallbona, en las pinturas de los dos retablos representados de la iglesia de San Jaume; en Llíria en la iglesia de la Sangre, a las capillas de San Esteban -la imagen del mismo santo- y la capilla de San Juan Baptista, -la imagen de un santo no identificado-; en Valencia se encuentran, en el reconditorio de la Catedral, y a San Juan del Hospital -los restos existentes- bajo el retablo de Santo Miquel de la misma capilla; en Xàtiva al retablo de Santo Nicolau y en el de la Virgen María de la ermita de Sant Feliu, y en el Calvario de la iglesia de San Pedro de la misma ciudad (ver llustración 2). 

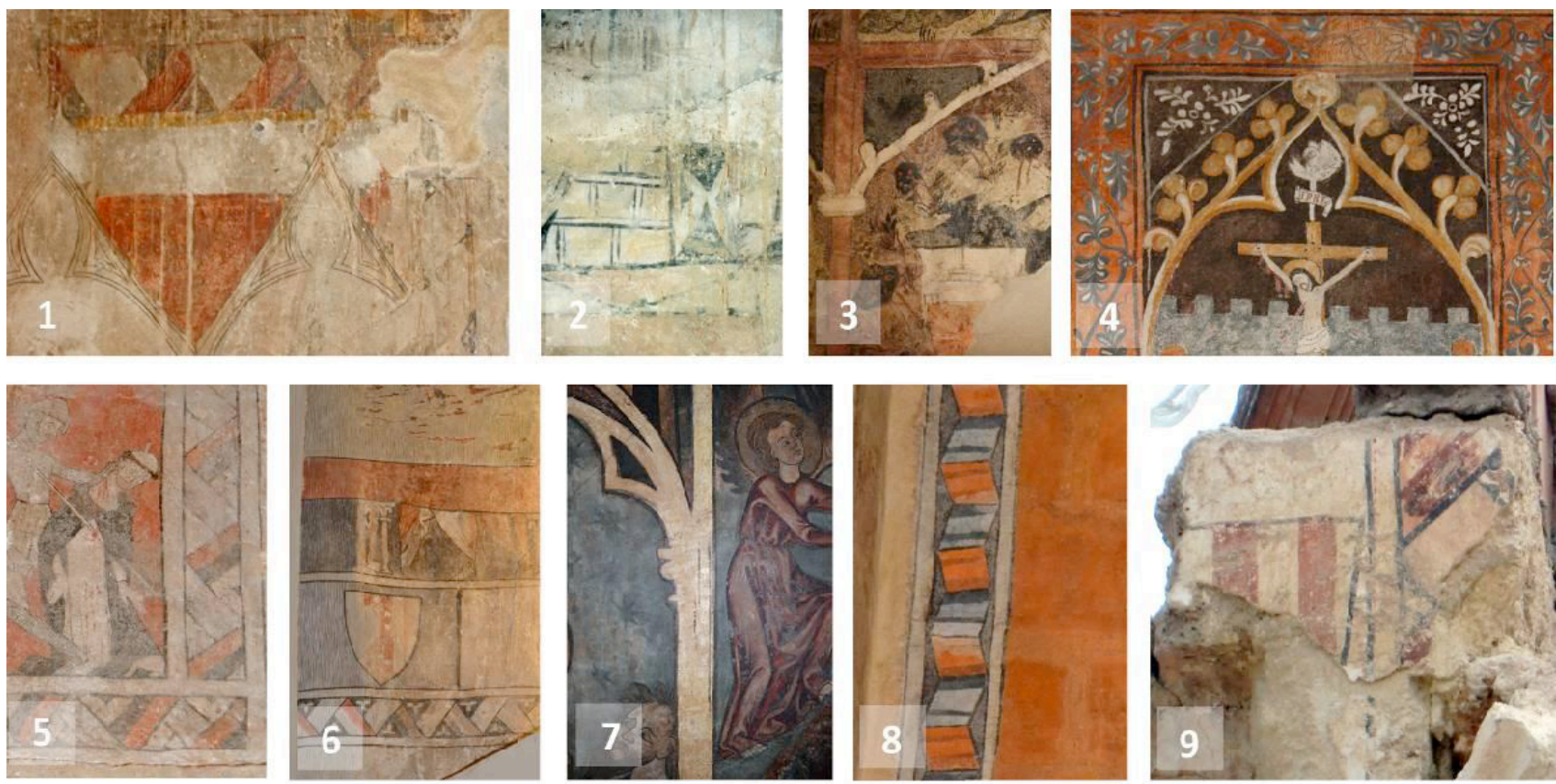

Ilustración 1
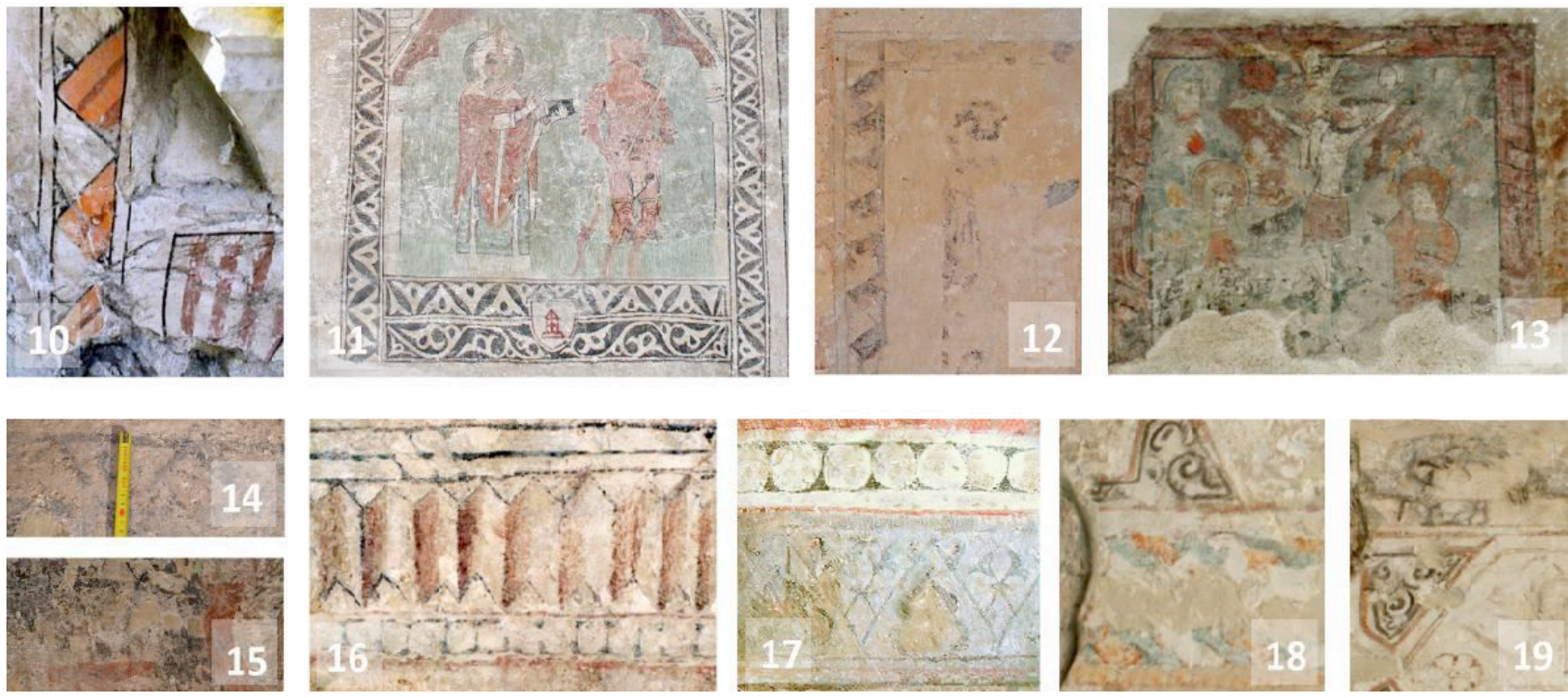

Ilustración 2

Escenas de Santos representados de forma individualizada se han localizado en Ademuz, a la ermita de la Virgen de la Huerta, donde hay una María Magdalena; en Castellfabib, un Santo Cristóbal con donante; en Xàtiva a la ermita de Sant Feliu, y en la iglesia de San Pedro, otras dos imágenes de Santo Cristóbal. En Llíria en la iglesia de la Sangre, a pesar de que muy mutilados, hay las representaciones de San Esteban y un Santo no identificado.

Temática propia de las órdenes mendicantes se han identificado: en Morella al Convento de San Francisco, la Danza de la Muerte y un Lignum Vitae; en Valencia en la iglesia de San Juan del Hospital Cruces propias de la orden hospitalaria.

En edificaciones civiles se han identificado escenas donde aparecen figuras humanas en escenas profanas que muestran la actividad cotidiana de la época, como es el caso del Palacio Castell de Llutxent donde se representan escenas de luchas entre caballeros; y al 
Palacio de En Bou en Valencia donde hay la escena de un alquimista y otros donde personajes individuales, entre ellos caballeros, personajes religiosos mitrados, reyes, etc.

Por último, se han identificado fragmentos de policromías donde aparecen figuras humanas, que por su descontextualización se desconoce aquello que podrían representar, están en Valencia en el Convento de Carmen los restos donde hay un par de personajes no identificados, que podrían ser campesinos; y en Gandía al Palacio Ducal, en la sala de la Cinta donde se conserva una franja con escenas figurativas muy mutiladas. Por otro lado sí son claras las representaciones de demonios que hay asociados en algunos santos, como están en Valencia en San Juan del Hospital, en la capilla de San Miguel en el retablo del mismo nombre; y en Xàtiva, en la ermita de Sant Feliu, en el retablo del Santo Nicolás.

De las pinturas a las cuales se ha tenido acceso o hay documentación al respeto, se ha podido tomar medidas de las representaciones figurativas humanas. Se han clasificado según las dimensiones de las mismas, para facilitar el posible estudio de transposición de modelos. Así se han distribuido en: menos de 35 centímetros de altura, entre 35 y $50 \mathrm{~cm}$, y más de $50 \mathrm{~cm}$.

- Menos de $35 \mathrm{~cm}$ están las pinturas de los personajes de las habitaciones del Convento de Carme en Valencia; las del Palacio Viejo de Llutxent y las del Palacio Ducal de Gandía.

- Entre 35 y $50 \mathrm{~cm}$ se encuentran las figuras en Morella de la Danza de la Muerte y del Lignum Vitae; en Castellfabib las del retablo de la Pasión, y el donante del Santo Cristóbal; en las de Vilafamés; en Alcublas las del retablo del San Antoni; en Llíria, en la iglesia de la Sangre las escenas del martirio de San Pedro de Verona; en la Pobla de Vallbona las del retablo de la Virgen María y el Calvario del retablo de los santos Abdón y Senén; En Valencia, las figuras del Reconditorio de la Catedral; y las de la Capilla de Santo Miquel a la iglesia de San Juan del Hospital; en Xàtiva, en la ermita de Sant Feliu, las figuras de las calles centrales de los retablos de Santo Nicolás, el Calvario del retablo del Salvador, y las de los laterales del retablo de la Virgen María.

- Más de $50 \mathrm{~cm}$ de altura: en Ademuz, la imagen de María Magdalena; en Castellfabib, el Santo Cristòbal; en Alcublas las figuras del Calvario; en Llíria las de la iglesia del Buen Pastor; también en Llíria las de San Esteban en la capilla del mismo nombre, y el santo no identificado a la capilla de San Juan Baptista; en la Pobla de Vallbona, las figuras titulares del retablo de los Santos Gil, Abdón y Senén; en Valencia las figuras del Reconditorio de la Catedral; también en Valencia las de la Capilla de Santo Miquel en la iglesia de San Juan del Hospital; en Carcaixent, las figuras -todavía ocultas- del retablo al presbiterio en el muro del lado del evangelio; en Xàtiva en la iglesia de San Pedro, el San Cristóbal, y el calvario; también en la capital de la costa, en la Ermita de Sant Feliu, las figuras centrales de los retablos de San Nicolás, El Salvador, y la Virgen María, y además el San Cristóbal; en Ontinyent las pinturas donde se representa el San Sebastián.

De este análisis se concluye que las figuras más grandes, corresponden a aquellas titulares de retablos o aquellas que representan imágenes de santos de forma individual, o forman parte de un calvario como escena única. Todos los personajes de las escenas no titulares de retablos tienen unas dimensiones entre 35 y 50 centímetros. Los personajes de menos de $35 \mathrm{~cm}$ se encuentran en decoraciones civiles, dentro de conjuntos seriados que decoran la casi totalidad de los menajes de una sala, como son las del PalacioCastell de Llutxent y las del Palacio de Borja de Gandía, y únicamente al edificio religioso al convento de Carme, en las habitaciones, se encuentra la figuración de la cual no se identifica el programa iconográfico que representa.

Grafitos (Dibujos) que han sido realizados sin color, por incisiones o sólo empleando carboncillo. Se han localizado en Llíria en la iglesia de la Sangre, en el interior del muro de la fachada; y en Catí en la Lonja, -a pesar de que parecen posteriores-, y se tienen noticias de los de la ermita de San Blas en Ayora.

Pinturas caligráficas identificativas de los personajes o de la escena donde se ubican, existe un buen número de ejemplos, como es el caso de la Anunciaciones de María, o incluso hay un identificativo de la autoría de la obra. Están escritos en latín o en catalán medieval y presentan dos tipos de caligrafía, una más redondeada y otra de caracteres más angulosos. En la mayor parte de los casos son monocromos, pero también hay dicromos. En ambas se emplean los puntos para separar las palabras -dos o tres puntos en vertical- 0 para señalar el final de frase, además de las abreviaturas a los casos escritos en latín, y las florituras.

Se han encontrado textos en Morella en los dos conjuntos originales de la sala capitular del convento de San Francisco. En la Danza de la Muerte conservada in situ los textos en latín y en catalán medieval, son muy extensos y de tetragramas que escriben parte de la danza "Ad mortem festinamus", recogida al Libro Rojo de Montserrat. En el Lignum Vitae, expuesto en el Museo de Castellón, hay restos de las inscripciones originales de las cuales no se puede leer el que dicen, sí se ha podido distinguir la palabra “...mortem..." . En Ademuz el texto identifica el personaje, así a la parte superior derecha de la escena hay la inscripción de Magdalena. En Castellfabib bajo el San Cristóbal, a sus pies bajo los pescados, se puede leer parte del texto original ": ... s: det peia :..." . En Alcublas se conservan al retablo de San Antonio restas de textos ilegibles a la escena de la Anunciación, además hay exenta la inscripción "en l'any de 1411 (1406) en lo present retable folumbrero [do]mingo Sebastián ". En la Pobla de Vallbona, en el retablo de los santos de la piedra los 
textos identifican los personajes San Abdón y San Senén, este segundo como "Sennen". En Llíria en la iglesia del Buen Pastor, hay la inscripción de la Anunciación de María. En Valencia a las escenas del reconditorio de la Catedral, con grafía parecida a la de la Magdalena de Ademuz, se identifican personajes y expresiones definitorias de la escena, con las inscripciones correspondientes a cada cual "IHS"; "Caifas"; "Axa Rex ludeorum"; "IHS:XPS" y "Pilatos". En la iglesia de San Pedro de Xàtiva se aprecia la mitad de una inscripción que no se distingue con claridad y se desconoce que citan, mientras que en los restos no legibles de la Sala de la Cinta del Palacio Ducal de Gandía, sí se sabe que es el que relatan gracias a la bibliografía disponible (ver llustración 3-4).
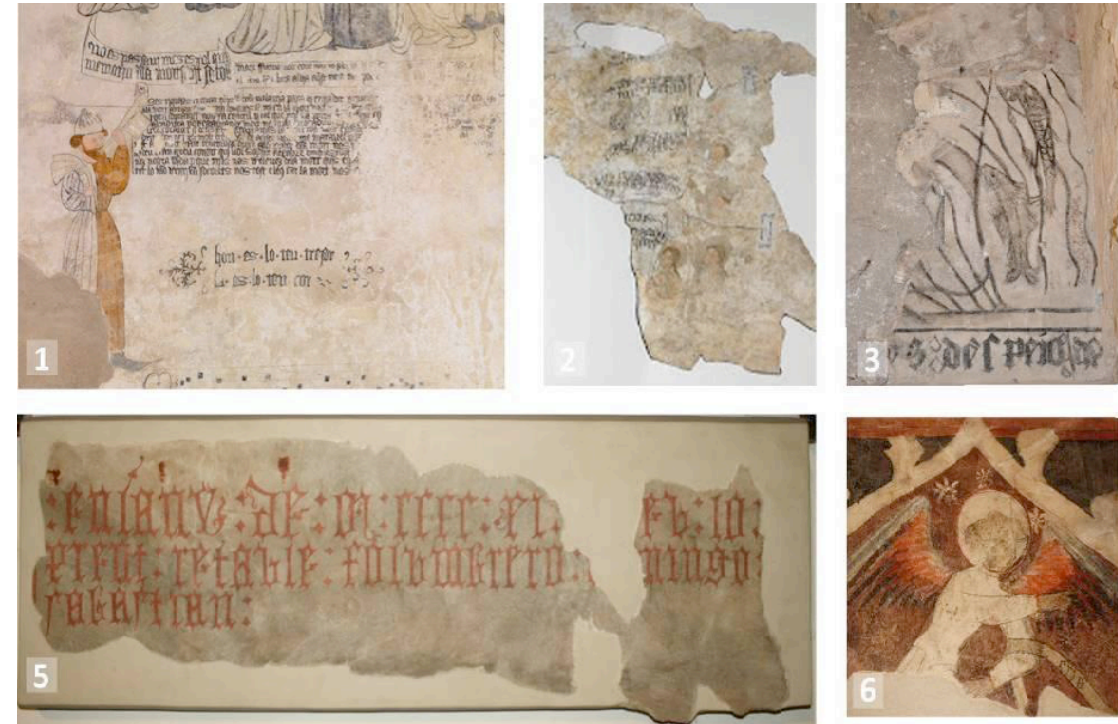
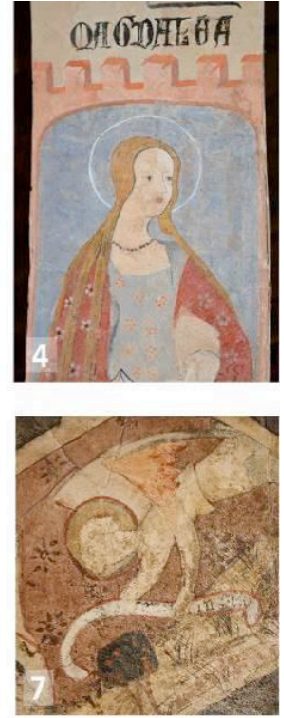

llustración 3
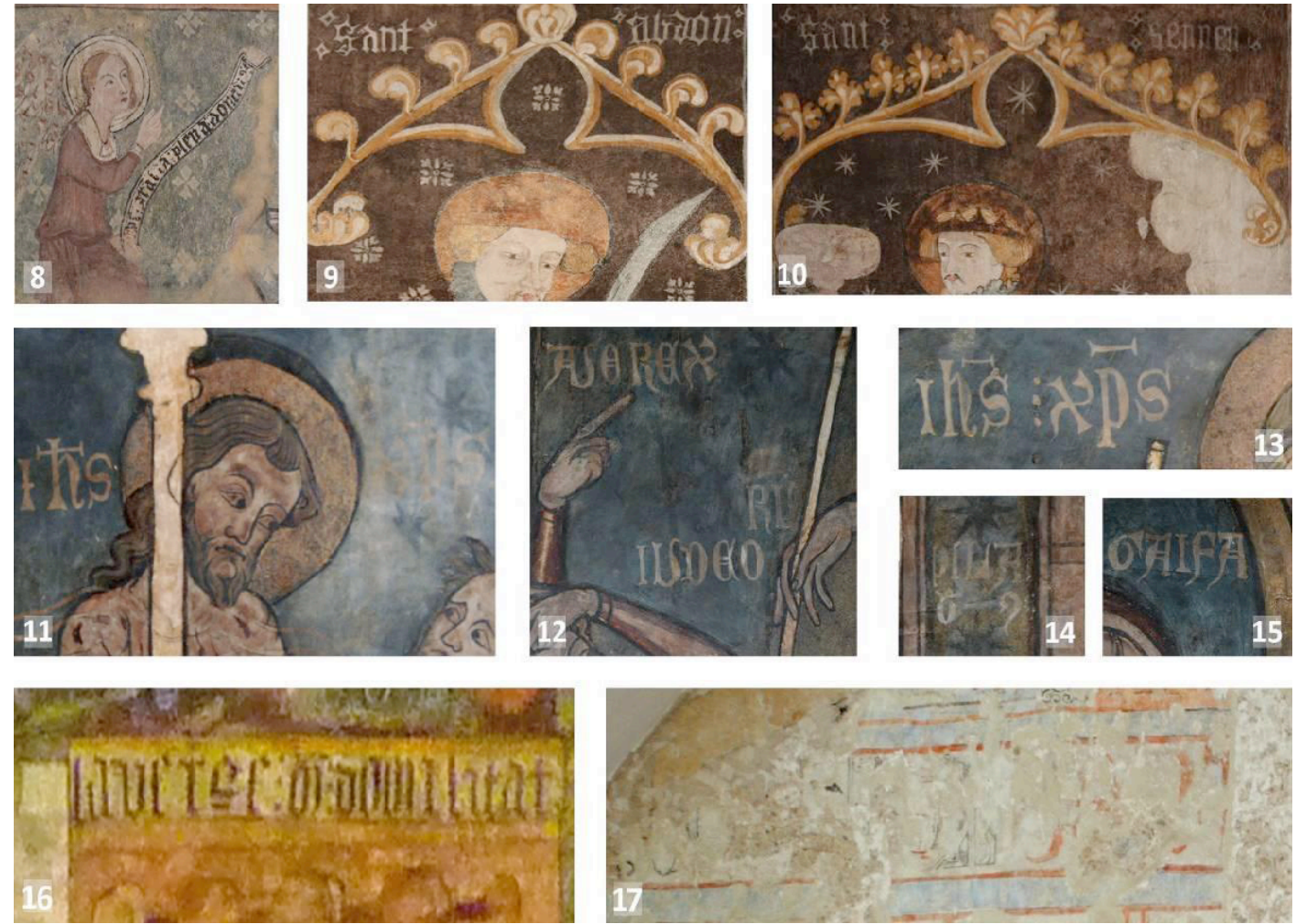

llustración 4

ANIAV Asociación Nacional de Investigación en Artes Visuales

This work is licensed under a Creative Commons Attribution-NonCommercial-NoDerivatives 4.0 International License (CC BY-NC-ND 4.0) 
Representaciones de animales se han identificado en escenas asociadas a las figuras humanas, o aisladas formando parte de un conjunto lúdico decorativo. Se identifican: en Morella, al Convento de Santo Francisco a la escena de la Danza de la muerte, ratas; en Catí animales diversos como aves y reptiles; en Castellfort en las escenas de la Epifanía y el Nacimiento de Cristo, el asno y el buey propios; en Castellfabib, en el retablo de la pasión, un asno, y a los pies del San Cristóbal peces; en Valencia en el convento de Carmen, en las habitaciones un ciervo, un asno y varios pájaros no identificados; también en Valencia al Palacio de en Bou, en la parte de la escena figurativa caballos, pájaros y el que parecen simios, en la parte del zócalo decorativo toda una serie de representaciones de animales reales y ficticios, donde hay aves de varias tipologías no identificadas, dragones, caballos, cerdos jabalíes, dromedarios, cabritos, leones, ciervos, bueyes, mamíferos alados, etcétera; en Llutxent al Palacio Viejo hay un friso figurativo con representaciones de caballos.

Los elementos decorativos identificados han sido de varios tipos, y se agrupan según el motivo general que se representa, así se clasifican segundos: decoraciones arquitectónicas, azulejerías, y sillares perfilados y/o fingidos imitando mármoles; frisos de influencia mudéjar con lacerias, cintas perladas, o cenefas vegetales o tipo dentado; zócalos donde hay un módulo repetitivo, cortinajes, elementos heráldicos, o tan sólo elementos de color o grafitos empleados para el proceso constructivo, como son líneas de nivel.

Por otro lado se han identificado decoraciones meramente arquitectónicas, como método para abaratar los costes que supondría el emplear los materiales originales que se imitan. Así se han simulado elementos constructivos cómo son azulejerías, perfilados de sillares y sillares imitando mármoles, o de ornamentación de muros y molduras de portadas con bandas de color, lacerias, formas vegetales, cortinajes o elementos heráldicos, o elementos residuales del proceso constructivo cómo son las líneas de nivel, en cuanto a las decoraciones a la arquitectura se separa entre azulejerías y perfilados de sillar.

De azulejerías hay ejemplos en Llíria, en la iglesia de la Sangre, en las bóvedas de varías capillas; y en Valencia, en el convento del Carmen en las bóvedas del claustro, y en los laterales del refectorio y aula capitular.

En los muros que rodean las pinturas son comunes las decoraciones arquitectónicas de las juntas o perfilados de sillares (ilustración 5), de las cuales se conservarán con seguridad más de las que aquí se citan, pues muchas veces no son fáciles de identificar entre los lucidos que las esconden, y por la pérdida de la policromía negra de los perfilados. En ocasiones dentro de las juntas de sillares se representan elementos heráldicos o decorativos como elementos florales. Se han encontrado: en la catedral de Valencia, en el interior de la puerta gótica y en los muros de la cámara secreta; en la iglesia de San Juan del Hospital localizadas en varios lugares, en los muros interiores a los pies de la nave central, en la capilla derecha del presbiterio y en la capilla de santo Miquel; en Carcaixent hay restos en el exterior, en los muros exteriores, localizados.

Además se han identificado decoraciones arquitectónicas, en otros edificios donde no se encuentra ninguna figuración, sólo se ha detectado este tipo de decoración. Estos edificios no mencionados anteriormente son: en Burriana la iglesia del Salvador, en las bóvedas del presbiterio se aprecia la imitación de azulejería; en Valencia hay restos de perfilados de sillares en varios edificios, en el claustro del convento de Sant Domenech, en la capilla lateral del lado del evangelio de la iglesia de San Martí, y a la iglesia de San Nicolás y San Pedro, en los laterales y en las bóvedas, bajo las pinturas murales barrocas de Dionís Vidal y a las capillas laterales de la nave central; en Alfahuir, en el convento de Santo Jerónimo dentro de la iglesia.

Se han identificado imitaciones de sillares tipos marmoleados en las habitaciones del convento del Carmen, y a la iglesia de San Juan del Hospital en Valencia, en el exterior del arco toral de la capilla de San Miguel.

También se han identificado líneas que responden al proceso constructivo del edificio, como son las líneas de nivel para marcar los niveles en las construcciones. De esta tipología se han identificado ejemplos en Valencia en las habitaciones del convento de Carmen; en Xàtiva en la ermita de Sant Feliu, sobre el retablo de Santo Nicolau, y en el de la Virgen María.

Elementos pétreos decorados con franjas de colores planos sólo o combinados con motivos vegetales se localizan en: Castellfabib en la iglesia de Ntra. Sra. De Ángeles; en la capilla de San Juan Bautista de la iglesia de la sangre de Llíria; en los arcos entre capillas del lado de la epístola a la catedral de Valencia, y en Carcaixent en la ermita de San Roque de Ternils. 

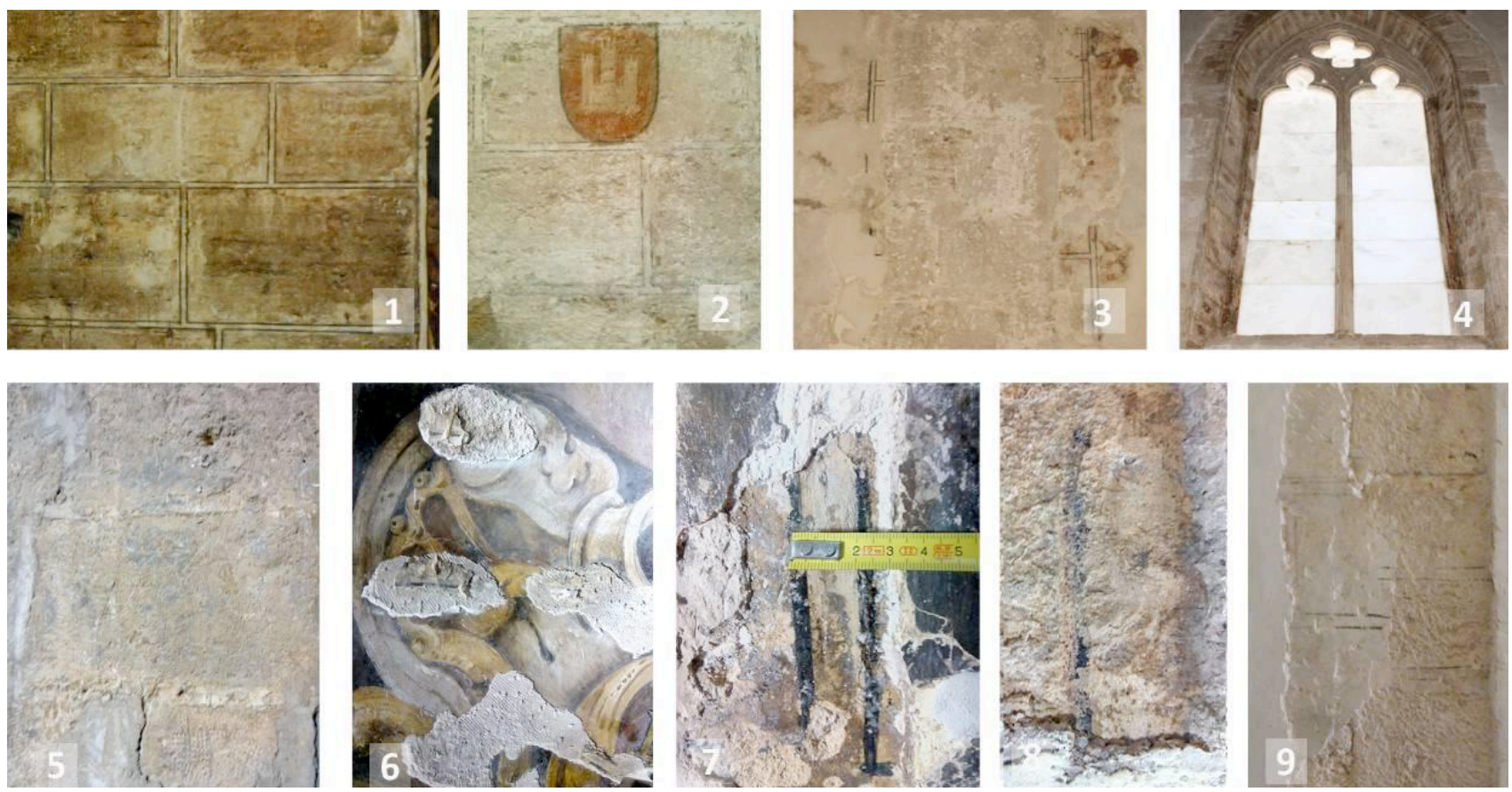

Ilustración 5

Elementos heráldicos, se han identificado en numerosos conjuntos donde están estos elementos, son identificativos de los señores, promotores de las obras, bien de los conjuntos pictóricos o benefactores de los edificios donde se ubican. Estos elementos decoran a menudo las capillas donde eran sepultadas las familias, los linajes de las cuales se representaban. Se han identificado de varias medidas y formatos, inscritos dentro de otros elementos o presentados de forma individual.

Como elementos únicos se han identificado escudos, de una medida mayor de $30 \mathrm{~cm}$ de altura (e inscritos en el interior de una orla, fruto de la evolución de una estrella de ocho puntas) a: Llíria en la iglesia de la Sangre, a la capilla de San Juan Baptista (en este caso se encuentran inmersos en perfiles de sillares policromados); en Valencia al convento de Carme, en el claustro y en las habitaciones; en la Catedral de Valencia a la Capilla de San Pedro; y en Xàtiva en la iglesia del convento de Sant Domenech.

Las representaciones heráldicas de menos de $30 \mathrm{~cm}$ que se han identificado, se localizan dentro de las decoraciones tipos friso, formando parte de las cenefas, o como en el caso de las pinturas de Santo Nicolau a la ermita de Sant Feliu de Xàtiva, formando parte del marco de las escenas. Se han encontrado este tipo de escudos de menos de $30 \mathrm{~cm}$ en: Albocàsser, en la ermita de los Santos Juanes; en Llíria en la capilla de San Juan Baptista, en Valencia, en la Catedral de Valencia al muro interno de la portada gótica, en el refectorio del convento de Carme en Valencia; en Xàtiva en el claustro del convento de Sant Domènech; en Llutxent en la sala noble del Palacio Viejo, y en Gandía en la Sala de la Cinta del Palacio Ducal (ilustración 6).

Representaciones edilicias, donde aparecen construcciones propias de la época, donde hay diversidad policroma se han detectado en: Castellfabib al retablo de la Pasión, en Llíria en el presbiterio de la iglesia de la Sangre; en Valencia en el Palacio de En Bou y en el Reconditorio de la Catedral; en Xàtiva en la iglesia de Sant Feliu en el retablo de San Nicolau y en el de la Virgen María. De tipo grafito ejecutadas con mono o bicromía, se encuentran en: la Lonja de Catí; y en Valencia en las habitaciones del Convento del Carmen, y en el Palacio de la Villa de Ontinyent. 

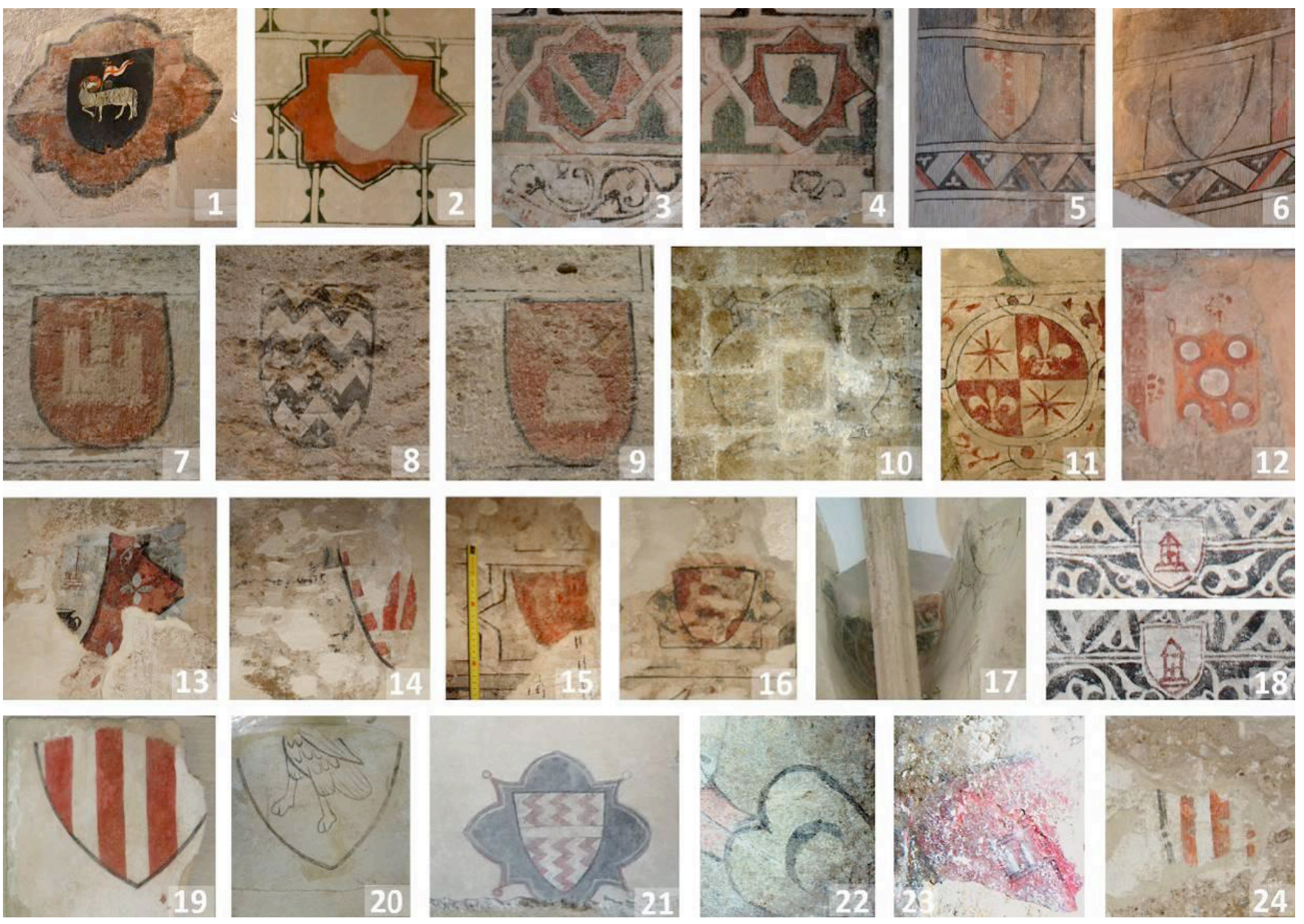

Ilustración 6

Frisos de influencia mudéjar (que muchas veces rematan por la parte superior de los cortinajes): en Valencia al refectorio del convento de Carme; en Llíria en la iglesia de la Sangre, a la capilla de San Juan Baptista; en Llutxent al Palacio Viejo, y en Gandía en la Sala de la Cinta.

Cortinajes. Otros elementos que se comparan, presentados en forma de mesa, son las decoraciones comunes de las escenas rematadas a la parte inferior con cortinajes. Estas teles pintadas se podrían interpretar a las obras religiosas como mesas de altar, mientras que a los edificios civiles servirían para cubrir los muros desnudos con una decoración coloreada. El hecho de poderlas comparar nos ayuda a identificar trazas de colores y formas poco definidas en algunos conjuntos, que de otra manera quedarían ignoradas. Cortinajes se representan y localizan como remado inferior de escenas figurativas, se encuentran restos de su existencia primigenia (de la cual sólo se conservan trazas) a: Llíria, en la capilla de San Juan Baptista; en Valencia, en la capilla de Santo Miquel de la iglesia de San Juan del Hospital y en el refectorio del Convento del Carmen; en Xàtiva, en el claustro del convento de San Domènech conservado parcialmente en una de las capillas; en Llutxent al Palacio Viejo que todavía se encuentra oculto bajo capas de morteros y pinturas; y en Valencia en la cámara secreta de la Catedral, donde se conserva el cortinaje completo (ilustración 7). 

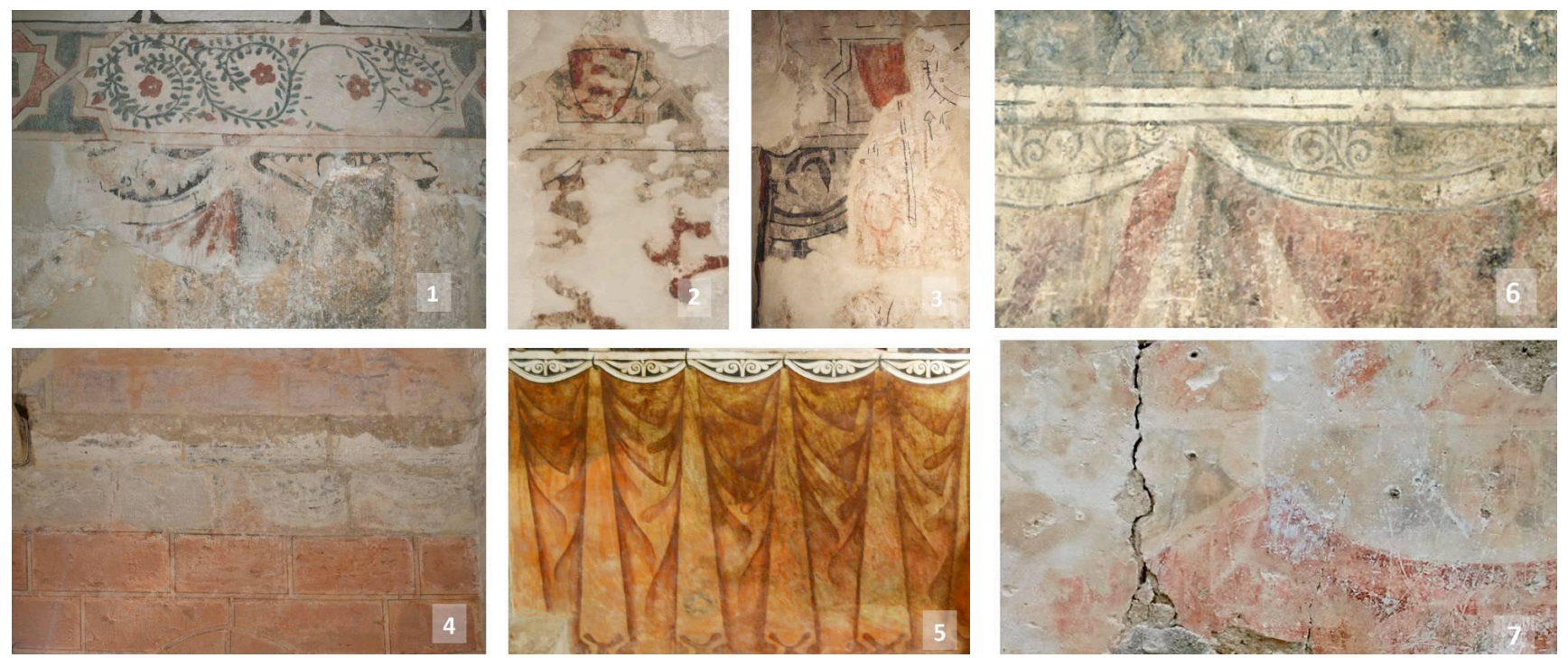

\section{Ilustración 7}
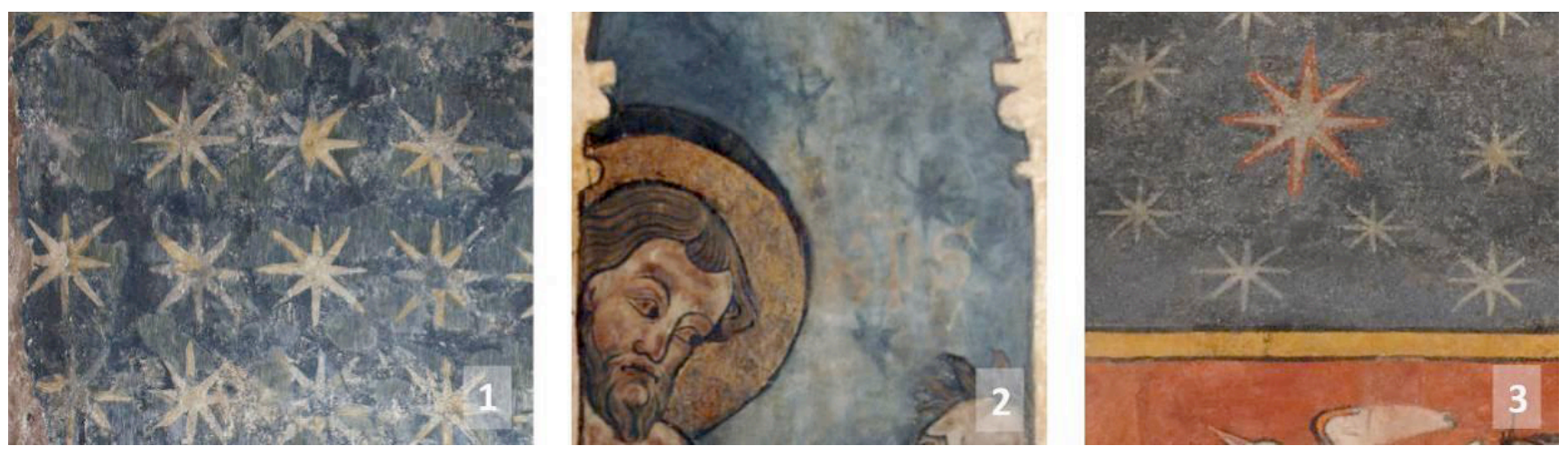

Ilustración 8

Por último, se han identificado anchas zonas de menajes totalmente decorados con un motivo único, elementos repetitivos cómo son las bandas de color o estrellas. Fundes con bandas de color que se han denominado fondos vallados se han visto a: Albocàsser, en la iglesia de los Santos Juanes; en Valencia al presbiterio de San Juan del Hospital; en Carcaixent en los menajes frontales de las capillas cuarta y quinta del lado del evangelio, y al arco tercero junto a la epístola de la ermita de San Roque; y en Xàtiva en la ermita de Sant Feliu se han identificado, arriba del retablo de la Virgen María, en la tercera capilla del lado de la epístola.

Otro motivo de fondos encontrados, son los de las zonas decoradas con estrellas (figura 8) sobre una tonalidad azul oscura, estos tipos de fondos estrellados se han identificado en la ciudad de Valencia a tres lugares: en el Palacio de En Bou, en la iglesia de San Juan del Hospital a la capilla de Santo Miquel, y en las pinturas de la Cámara secreta de la Catedral; que además presentan entre ellos dimensiones parecidas, las estrellas varían entre 8 y $10 \mathrm{~cm}$ de estatura.

\section{CONCLUSIONES.}

A partir de la información presentada, se extrae que hay un gran número de conjuntos que presentan escenas figurativas de tipo religioso, más de un tercio del total; aproximadamente una quinta parte son elementos decorativos, y otra parte similar de elementos de imitación de materiales constructivos o propios de este proceso, una octava parte serían las escenas de temática civil, y casi una décima parte corresponden a conjuntos todavía para conocer.

Estudiando los elementos por localidades, se observa un gran predominio de obras conservadas en las capitales y ciudades más pobladas e importados de la época, como son Valencia y Xàtiva. Se supone que aquellas que se han conservado y se han descubierto hasta el momento son mucho menos de aquellas ejecutadas, dado que muchas han desaparecido y otras que se espera, todavía estén por 
Mifsud, Aurora Rubio; Ma Antonia Zalbidea Muñoz

Estudio comparativo de la pintura mural gótica valenciana a partir de elementos de estilo y materiales representativos

III CONGRESO INTERNACIONAL DE INVESTIGACIÓN EN ARTES VISUALES :: ANIAV 2017 :: GLOCAL [codificar, mediar, transformar, vivir] http://dx.doi.org/10.4995/ANIAV.2017.5628

descubrir. Esta es la razón por la cual éste es un estudio vivo, que se ve ampliado y cambia con las continuas intervenciones en los edificios y nuevos descubrimientos de pinturas.

Por el momento se han estudiado los elementos de todos los conjuntos de forma individual, analizándolos de forma comparativa entre ellos. Se ha proseguido con la investigación sobre la transposición de modelos de rostros y vestiduras dentro de una misma obra, a la que en este caso se ha tenido acceso físico, la de la Cámara secreta de la Catedral de Valencia. Para encontrar paralelismos en cuanto a la ejecución todavía resta comparar estos modelos con otras obras de dimensiones y características parecidas, y completar así el estudio.

Los elementos decorativos por un lado y estos modelos de rostros y vestiduras, corroboran la existencia de material comunitario de taller, "libros de muestras", hecho ya aceptado por toda la crítica.

\section{FUENTES REFERENCIALES.}

RUBIO MIFSUD. A, ZALBIDEA MUÑOZ, M. A. (2014) La pintura mural gòtica lineal a territori valencià. Estudi i anàlisi per a la seua conservació. I Encuentro de Estudiantes de Doctorado de la Universitat Politècnica de València.

RUBIO MIFSUD. A, ZALBIDEA MUÑOZ, M. A. (2014). Estudio comparativo de materiales y técnicas en tres conjuntos de pintura mural del periodo gótico lineal en territorio valenciano. Jornadas de Investigación Emergente en Conservación y Restauración de Patrimonio, Emerge, Universitat Politècnica de València. ISBN: 978-84-9048-317-6.

RUBIO MIFSUD, A (2015): «La pintura mural gòtica lineal a territori valencià. Statu Quo del corpus conegut. Estudi i anàlisi per a la seua conservación, Tesis doctoral, Departament de Conservació i Resturació de Béns Culturals. Universitat Politècnica de València. Disponible on line; https://riunet.upv.es/handle/10251/59466

RUBIO MIFSUD. A, ZALBIDEA MUÑOZ, M. A (2016): Posada en valor de la pintura mural gòtica lineal a territori valencià. Un cas a descobrir: el Palau-Castell de Llutxent, EN: Archivo de Arte Valenciano, № 97, pp. 37-52. ISSN: 0211-5808.

\section{ILUSTRACIONES.}

Ilustración 1. Cuadro comparativo de cenefas y marcos identificados: 1.Vilafamés. 2. Castellfabib. 3. Alcubles. 4. La Pobla de Vallbona. 5 i 6 Llíria. 7-15. Valencia.

Ilustración 2. Cuadro comparativo de cenefas y marcos identificados: Valencia. 9 i 10-15. Xàtiva. 16 i 17 Llutxent. 18 i 19 Gandía.

Ilustración 3. Cuadro comparativo de los textos identificados: 1 y 2. Morella. 3. Castellfabib. 4. Ademuz. 5-7. Alcublas. 8. Llíria.

Ilustración 4. Cuadro comparativo de los textos identificados: 9 y 10. La Pobla de Vallbona. 11-15, Catedral de Valencia. 16 . Xàtiva. 17. Gandía.

Ilustración 5. Cuadro comparativo de los juntas de sillar identificadas. 1 y 2. Catedral de Valencia. 3-8. Valencia. 9. Alfahuir.

Ilustración 6. Cuadro comparativo de los elementos heráldicos identificados. 1-6. Llíria. 7-11. Valencia. 12. Castellfabib. 13-17. Valencia. 18-21. Xàtiva. 22 y 23 Llutxent. 24. Gandía.

Ilustración 7. Cuadro comparativo de los cortinajes identificados. 1. Llíria. 2-5. Valencia.

Ilustración 7. Cuadro comparativo de los juntas de sillar identificadas. 4. Valencia. 6. Llutxent. 7. Xàtiva.

Ilustración 8. Cuadro comparativo de los fondos estrellados identificados. 1-3. Valencia.

\section{AGRADECIMIENTOS}

Al grupo de investigación MAGISTRI MEDITERRANEI: MOVILIDAD Y TRANSFERENCIA ARTÍSTICA EN EL MEDITERRÁNEO MEDIEVAL (1187-1388): ARTISTAS, OBJETOS Y MODELOS grupo de investigación (GdR) de la UAB (Departament d'Art i Musicología), del cual formamos parte. $Y$ a través del cual se estudian las técnicas de análisis de laboratorio el trabajo, la formación, el aprendizaje y la organización de los pintores, escultores y arquitectos. PROYECTO I D i. UNIVERSITAT AUTÒNOMA DE BARCELONA (UAB). Programa Estatal de Fomento de la Investigación Científica y Técnica de Excelencia, Subprograma Estatal de Generación de Conocimiento, en el marco del Plan Estatal de Investigación Científica y Técnica y de Innovación 2016-2019. Redes de Excelencia. 